\title{
Adjustment of Liquid Production in Reservoir with Handling Capacity Constraints
}

\author{
Jie Tan*, Dong Zhang, Dongdong Yang, Songru Mou, Peng Qin \\ Bohai Oilfield Research Institute of CNOOC Ltd.-Tianjin Branch, Tianjin, China \\ Email: `tanjie3@cnooc.com.cn
}

How to cite this paper: Tan, J., Zhang, D., Yang, D. D., Mou, S. R., \& Qin, P. (2019). Adjustment of Liquid Production in Reservoir with Handling Capacity Constraints. Journal of Geoscience and Environment Protection, 7, 18-25.

https://doi.org/10.4236/gep.2019.74002

Received: March 16, 2019

Accepted: April 7, 2019

Published: April 10, 2019

Copyright $\odot 2019$ by author(s) and Scientific Research Publishing Inc. This work is licensed under the Creative Commons Attribution International License (CC BY 4.0).

http://creativecommons.org/licenses/by/4.0/

\begin{abstract}
An oilfield was an oil reservoir with strong bottom water in offshore, the water cut was as high as $96 \%$. In the high water cut stage, the most effective way of increasing oil production was to extract liquid and increase oil. The processing capacity of oilfield fluid was limited by the conditions. By using Petrel-RE-2017 software, combining reservoir engineering and percolation mechanics methods, this paper analyzes the effect of large-scale liquid pumping, expands coverage and shut-in coning in oil reservoirs with bottom water, and formulates the adjustment strategy of single well production structure of the whole oilfield. It was confirmed that large-scale liquid production can expand coverage and shutting down well can reduce water cut. It can provide reference and guidance for oil field with strong bottom water when it encounters bottleneck of liquid treatment capacity.
\end{abstract}

\section{Keywords}

Strong Bottom Water Reservoir, High Water Cut, Liquid Production Structure Adjustment, Maximum Liquid Production Capacity, Maximum Reasonable Pressure, Bottom Water Coning

\section{Introduction}

Usually, oil wells had been abandoned in the case of high water cut. So for oilfields with super high water cut and limited fluid, there was little research on what measures should be taken to increase oil production. At the same time, existing studies had shown that under normal circumstances, a large amount of liquid extraction will cause water content to rise. And Liang Dan and others also analyzed that the increase in oil produced by shut-in cone killing was less than that produced by open-hole production, that was, shut-in cone killing was not conducive to oil increase. At the same time, Zhang Jin-qing et al. analyzed the 
maximum fluid production capacity of a single well by studying the dimensionless fluid production index (Liang et al., 2012, Zhou, 2009, Li, 2005, Li, 2002, Xiao et al. 2009, Kang et al., 2011, Wang et al. 2011). However, there are few studies on both fluid extraction and shut-in pressure cone. In this paper, through reservoir engineering and seepage mechanics combined with field technology and reasonable production system research, a reasonable allocation strategy was obtained for single well fluid production in offshore strong bottom_water reservoirs. At the same time, through field experiments, it could achieve the effect of increasing oil.

\section{Analysis of Maximum Fluid Production Capacity}

The main purpose of this adjustment is to optimize and adjust the liquid production of a single well and extract liquid from a single well in batches so as to improve the oil field production.

It has the advantages of wide application range, high prediction accuracy and high practical value. Therefore, this method is selected as the recommended method for adjusting the production structure of this oilfield.

See formula for calculation of Guangshi water drive curve (Clark \& Pilehvari, 1993):

$$
N_{P}=N_{R}-a \cdot \frac{N_{p}^{2}}{W_{P}^{q}}
$$

where, $a, q$ is coefficient; $N_{P}$ is Cumulative oil production, $10^{4} \mathrm{~m}^{3} ; N_{R}$ is Water drive movable oil reserves, $10^{4} \mathrm{~m}^{3} ; W_{P}$ is cumulative water production $10^{4} \mathrm{~m}^{3}$.

On the relation curve of water cut and cumulative oil production of single well, select the point representing the current actual production status, as shown in Figure 1. The slope and intercept of the broad water drive curve can be obtained by the linear regression of the above selection stage, and the correlation coefficient can be calculated at the same time. Adjust the Q value to maximize the correlation coefficient, as shown in Figure 2. At the same time, ensure that the predicted cumulative water production and the average water content of each stage are consistent with the actual situation (see Figure 3 ). Then, the oil phase index and the water oil flow ratio $\mathrm{m}$ are obtained by the formulas (2), (3) and (4).

$$
\begin{gathered}
n_{o}=1+\frac{1}{q} \\
n_{w}=\frac{2}{q}-1 \\
M=2\left(n_{o}-1\right) a^{n_{o}-1} N_{R}^{n_{o}-2}
\end{gathered}
$$

According to the obtained oil phase index $n_{o}$, water phase index $n_{w}$ and water oil mobility ratio $\mathrm{m}$, dimensionless production index is obtained (Zhang et 
al., 2013). The dimensionless index of liquid production calculation formula is shown in formula (5). The calculation results are shown in Figure 4.

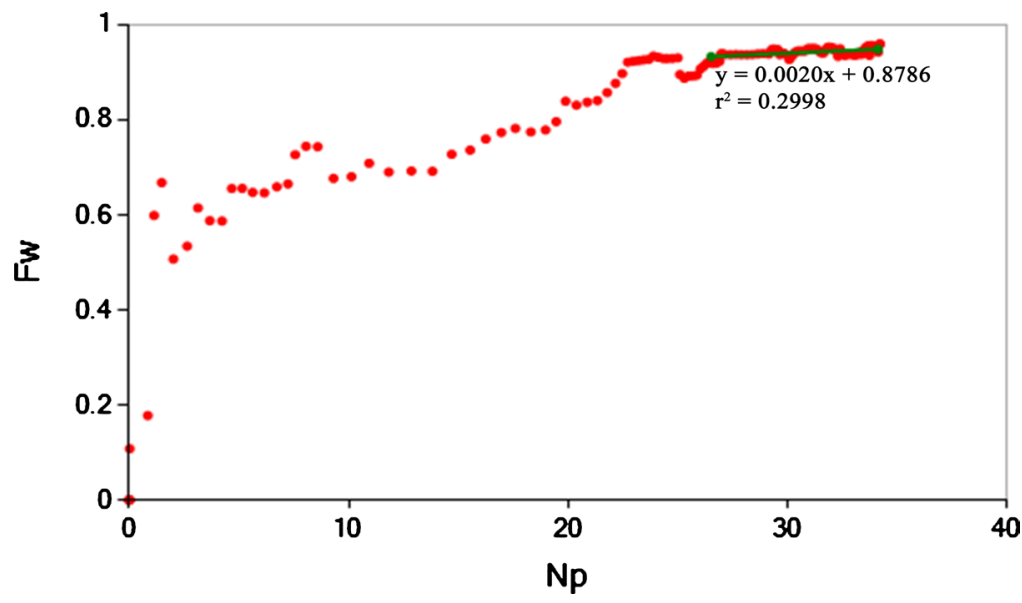

Figure 1. Relation curve between water content and cumulative oil production.

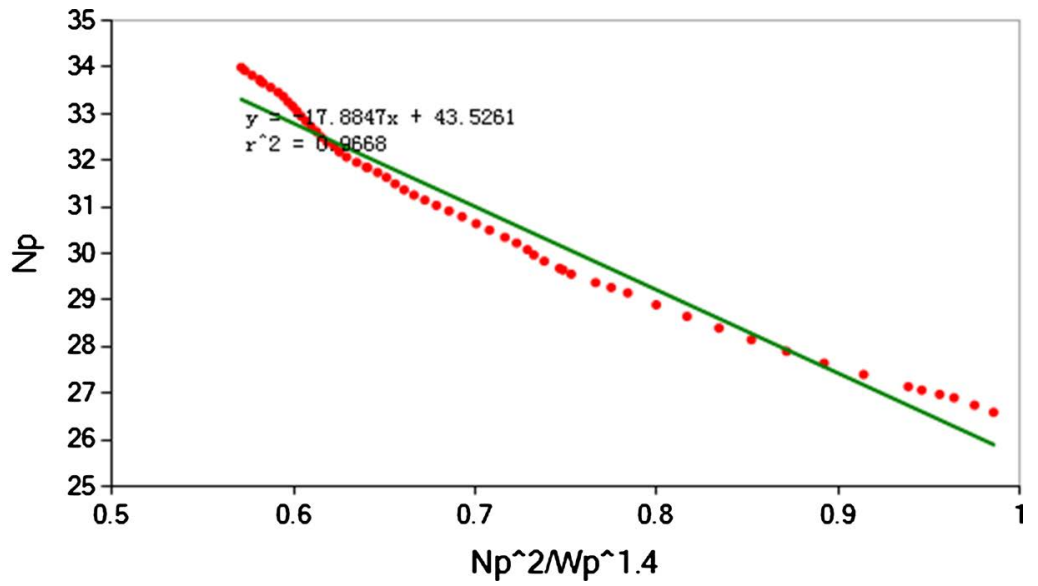

Figure 2. Guangshi water drive curve fitting diagram.

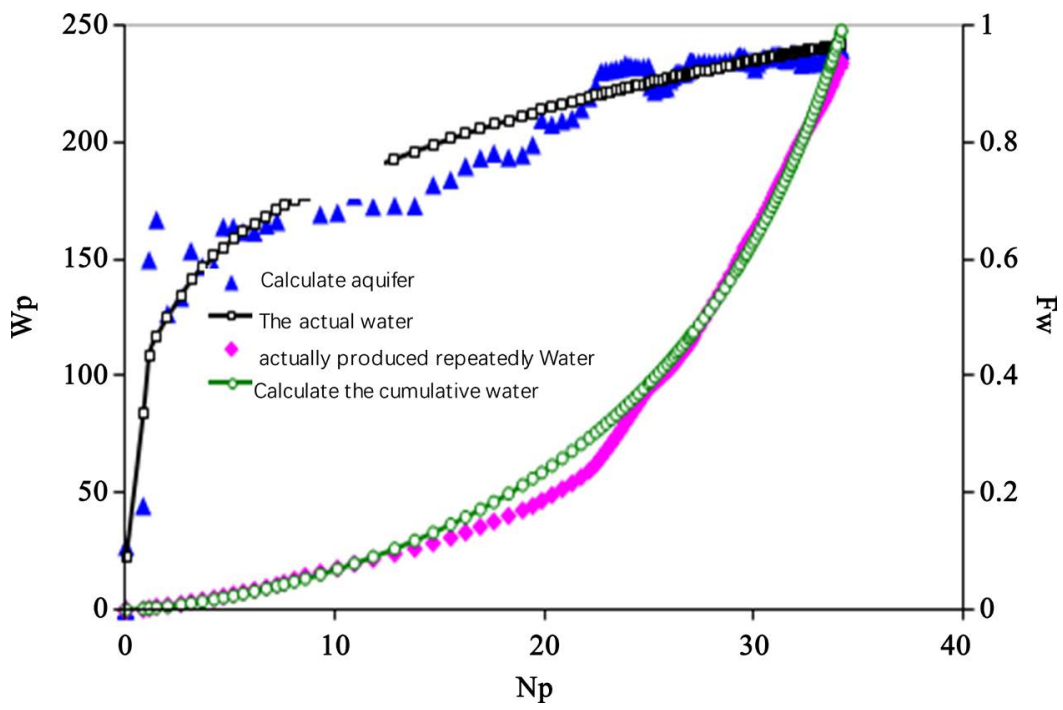

Figure 3. The fitting diagram of water yield and water content. 


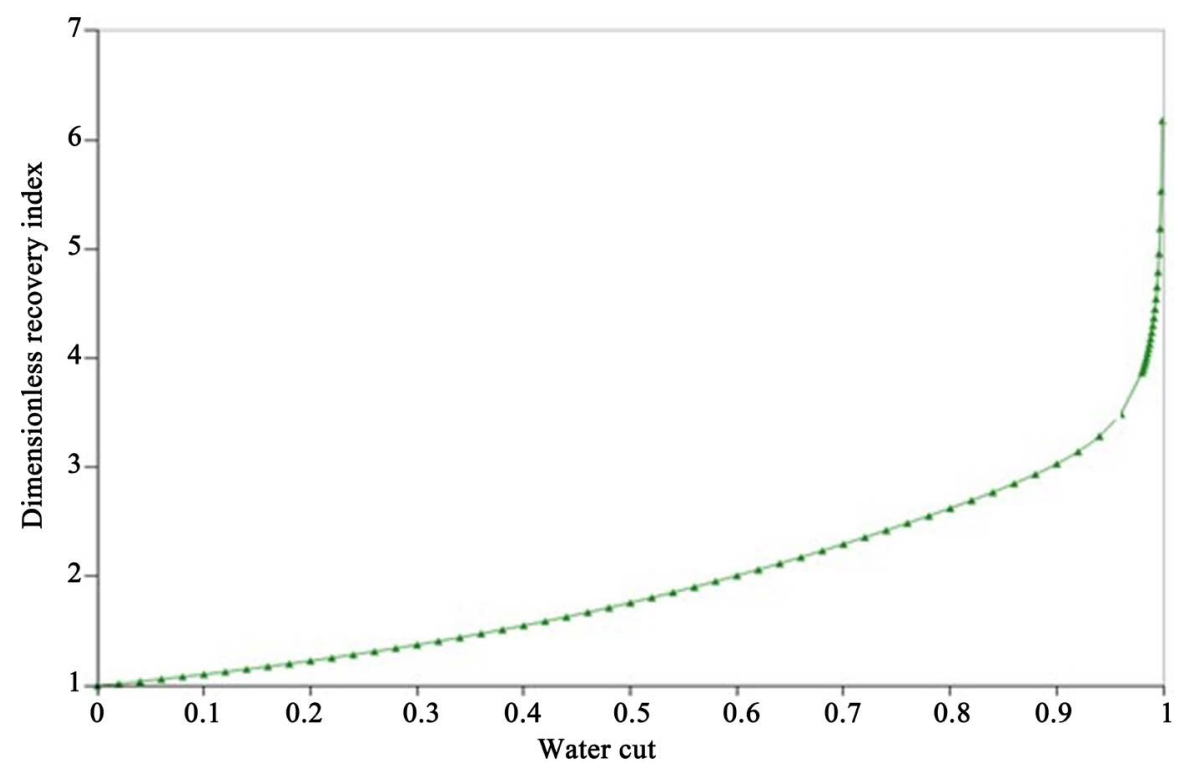

Figure 4. Graph of relation between dimensionless recovery index and water content.

$$
J_{D L}=\frac{1}{\left(1-f_{w}\right)\left[1+0.006738 \exp \left(\frac{3.5 n_{w}+6.5 n_{o}}{n_{w}+n_{o}}\right)\left(\frac{1}{M} \frac{f_{w}}{1-f_{w}}\right)\right]^{n_{w}}}
$$

where, $n_{o}$ is oil phase index, $n_{w}$ is water phase index, $N_{P}$ is dimensionless index of liquid production, $f_{w}$ is water cut, $M$ is mobility ratio.

\section{Analysis of Shut-In Coning}

In order to adjust the fluid production structure, Secondly, it is necessary to analyze the effect and time of the cone pressing.

After shut-in, the gravity difference between formation water and oil gradually falls back to point $\mathrm{A}$ through the water at point $\mathrm{B}$, thus forming the coning effect (Huang, 1997; Xu et al. 2013). The time required for bottom water to fall back to the oil-water interface from the bottom of the well:

$$
t_{B A}=\frac{\mu_{W} \varnothing\left(h-h_{P}\right)}{K \Delta \rho_{\text {wo }} g}
$$

where $t_{B A}$ is the time when bottom water falls back from bottom hole to crude oil-water interface, the unit is $\mathrm{d}$. $\Delta \rho_{\text {wo }}$ is the formation water oil density difference, the unit is $\mathrm{kg} / \mathrm{m}^{3} . g$ is gravity acceleration, the unit is $\mathrm{m} / \mathrm{s}^{2} . \mu_{W}$ is viscosity of water, the unit is mPa.s. $\varnothing$ is formation rock porosity, the unit is $\%$. $K$ is reservoir permeability, the unit is $\mathrm{mD}$.

By numerical simulation analysis, the effect of dewatering also exists in shut in pressure cone of heavy oil bottom water reservoir (Figure 5). The parameters of the model are: the water and oil volume is 100 , reservoir thickness $\left(H_{i}\right)$ is $15 \mathrm{~m}$, porosity is $30 \%$, horizontal permeability $\left(K_{h}\right)$ is $3000 \mathrm{md}$, vertical permeability $\left(K_{v}\right)$ is $300 \mathrm{md}$, initial oil saturation is 0.75 , formation of crude oil viscosity 


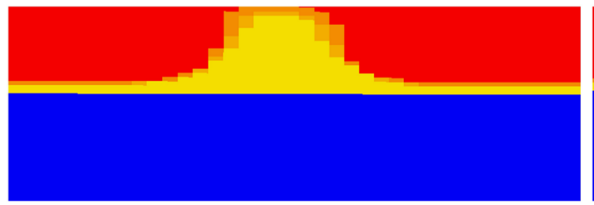

Before shut in

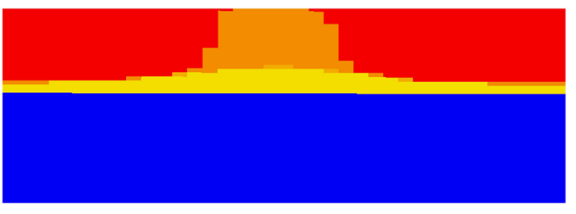

After shut in

Figure 5. Schematic diagram of well shut in cone killing effect.

$\left(\mu_{o}\right)$ for $30 \mathrm{mPa} \cdot \mathrm{s}$, crude oil density $\left(\rho_{o}\right)$ is $950 \mathrm{~kg} / \mathrm{m}^{3}$, formation water apparent viscosity $\left(\mu_{w}\right)$ is $0.45 \mathrm{mPa} \cdot s$, formation water density $\left(\rho_{w}\right)$ is $1000 \mathrm{~kg} / \mathrm{m}^{3}$.

\section{The Analysis of Rational Production Allocation}

In order to develop oilfields at a high speed, oil production was the most important index. According to the specific conditions of oilfields, liquid production was limited, and can only be developed at a high speed by adjusting the structure of liquid production. Combined the lifting capacity and cone pressing effect, and considered the conditions of field implementation at the same time (Xu et al. 2013; Wang et al. 2019; Tan et al. 2019; Lei et al. 2019). The development strategy was given as follows:

1) The purpose of increasing oil and reducing water can be realized through the adjustment of extracting and reducing liquid between oil wells.

2) The adjustment of oil well liquid production should first meet the reasonable development of the oil field, and on this basis, it should also be based on the actual engineering conditions of the oil field, such as oil field liquid processing capacity, offshore pipeline transportation capacity, platform power and other conditio:

a) There is a certain margin in the engineering conditions, so it should be considered to optimize the extraction well through theoretical research and actual production analysis.

b) One of the engineering conditions has reached saturation (especially the liquid treatment capacity). In the long term, it is necessary to reconstruct the relevant facilities according to the research results of the geological reservoir; in the stage, it is possible to adjust the liquid production between the oil wells, so as to achieve the purpose of increasing oil and reducing water by adjusting the liquid extraction/drop between the oil wells on the premise that the liquid production of the oil field remains unchanged.

3) Considering the characteristics of bottom water reservoir development, under the condition of limited engineering treatment, measures such as shut in, cone killing and rotary production can be taken to adjust the liquid production structure.

\section{The Analysis of the Field Test Result}

Take A oilfield as an example, A oilfield has been exploited for 25 years, and the water cut is as high as $97 \%$, and the daily liquid production is as high as $60,000 /$ day. Due to limited offshore facilities, the liquid treatment of the oilfield 
has been completed. Saturated, unable to increase oil through liquid extraction,.

\subsection{Selection of the Wells with Liquid Extraction Production}

According to the previous analysis of the maximum liquid production capacity, the critical pressure of sand production and degassing for all single wells in A oilfield are calculated. The maximum liquid production under the maximum bottom hole flow pressure is calculated by choosing the low value as the maximum bottom hole flow pressure. Combining with the maximum liquid production under the limit of single well pump and ground equipment, the low value is selected as the maximum liquid production of single well, and finally the space for liquid extraction and water cut are selected. Relatively low (water cut less than $97 \%$ ) wells carry out fluid extraction.

\subsection{The Increment of Oil Production under the Condition of Increase Liquid Production}

Through field experiments, the production of B well has been greatly increased from 1700 cubic metres per day to 2761 cubic metres per day, the daily oil production has increased by 73 cubic metres meters, and the water cut has decreased by $1.4 \%$ And through Petrel-RE-2017 mechanism model, the influence can be extended by extracting liquid to increase oil production (Figure 6).

By calculating the fluid increment of a single well after lifting, assuming that the water cut is constant, the oil increment of a single well is proportional to the fluid increment. Thus, the oil increment after single well lifting is calculated to be $139.0 \mathrm{~m}^{3} / \mathrm{d}$.

A Oilfield is now in a saturated state of liquid handling capacity. The total of $4000 \mathrm{~m}^{3} / \mathrm{d}$ of fluid is extracted from 36 wells. Some wells need to let off fluid. In order to achieve the goal of high-speed development of offshore oilfields, all wells in A Oilfield were sorted according to water cut, and the highest water cut
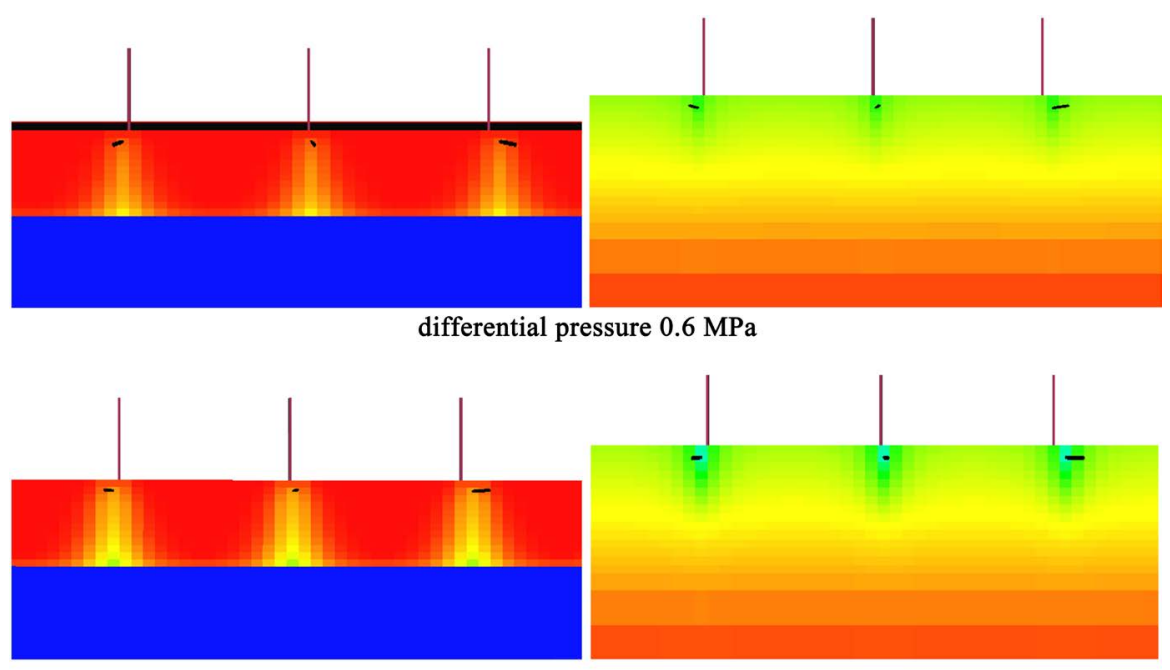

differential pressure $0.9 \mathrm{MPa}$

Figure 6. Scope of sweep under different pressure difference. 
wells were selected to shut down and let off fluid. 6 wells will increase oil production by $139.0 \mathrm{~m}^{3} / \mathrm{d}$ and shut down 5 wells, resulting in a loss of $38.3 \mathrm{~m} / \mathrm{d}$. Finally, reasonable allocation of liquid yield per well is adopted to increase oil production. After shutdown of high water wells, after a certain period of gravity coning, re-opening takes part in a new round of fluid production structure adjustment.

\section{Conclusion}

Based on reservoir engineering and seepage mechanics combined with field technology, the adjustment of production structure in A oilfield was studied, and the following conclusions and understandings were obtained:

1) The generalized water drive curve method can be applied to strong bottom water reservoir, and the dimensionless production index of single well can be obtained by this method.

2) Effect of high water bearing well passing through shut in pressure cone.

Through the method of Guangshi water drive curve, considering the surface equipment, combined with the effect of shut in cone pressure, it can effectively guide the adjustment of liquid production structure of strong bottom water reservoir in high water cut stage.

\section{Conflicts of Interest}

The authors declare no conflicts of interest regarding the publication of this paper.

\section{References}

Clark, P. E., \& Pilehvari, A. (1993). Characterization of Crude Oil-in-Water Emulsions. Journal of Petroleum Science \& Engineering, 9, 165-181. https://doi.org/10.1016/0920-4105(93)90013-5

Huang, R. C. (1997). Application of Structural Adjustment of Liquid Production in Fault Block Oilfield Development. Fault Block Oil and Gas Field, 4, 38-41.

Kang, K., Feng, M., \& Li, Y. L. (2011). Study on the Method of Solving Critical Production Pressure Difference Parameters. Inner Mongolia Petrochemical Industry, No. 5, 121-123.

Lei, Z.-X., Mu, L. X., Zhao, H. et al. (2019). Automatic Optimization Technology of Liquid Production Structure in Late Stage of Water Flooding Reservoir. Petroleum Exploration and Development, 46, 763-767. https://doi.org/10.1016/S1876-3804(19)60238-7

Li, C. L. (2005). The Principle of Reservoir Engineering. Beijing: Petroleum Industry Press.

Li, Y. C. (2002). Oil Production Engineering. Beijing: Petroleum Industry Press.

Liang, D., Zeng, X. L., \& Fang, M. J. (2012). The Effect Analysis of Shut-In Coning Control. Petroleum Drilling Technology, 40, 82-85.

Tan, J., Hou, Y. W., Peng, Q. et al. (2019). Adjustment of Liquid Production Structure in High Water-Cut Stage of Offshore Strong Bottom Water Reservoir. Xinjiang Petroleum \& Natural Gas, 15, 62-65. 
Wang, F. Q., Cheng, M. J., \& Cheng, Z. L. (2011). Strategy and Effect of Offshore Oil Field Development Adjustment in Bohai Sea. Journal of Petroleum and Natural Gas, 33, 148-151.

Wang, S. T., Feng, H. C., \& Zheng, H. (2019). Research on Intelligent Adjustment of Liquid Production Structure in Heavy Oil Field in High Water-Cut Period. Xinjiang Petroleum and Natural Gas, 15, 48-51.

Xiao, C. Y., Li, W., \& Xiao, S. P. (2009). Production Mechanism and Rising Law of Water Cut for Edge and Bottom Water Reservoir. Fault-Block Oil \& Gas Field, 16, 68-70.

Xu, B., Dai, L., Xie, M. Y. et al. (2013). Water Horizontal Well Single Well Liquid Extraction Machine Selection. Science, Technology and Engineering, 13, 153-156.

Zhang, J. Q., An, G. R., Xu, J. F. et al. (2013). Adaptability Analysis and Application of Water Flooding Curve. China Offshore Oil and Gas, 25, 56-60.

Zhou, S.-W. (2009). Development Practice of Typical Offshore Oil Fields in China (pp. 28-29). Beijing: Petroleum Industry Press. 